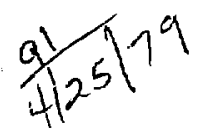

\title{
AN INTRODUCTION TO SELF-INDUCED RAINOUT
}

C. R. Molenkamp

February 1979

Work performed under the auspices of the U.S. Department of

Energy by the UCLLL under contract number W-7405-ENG-48

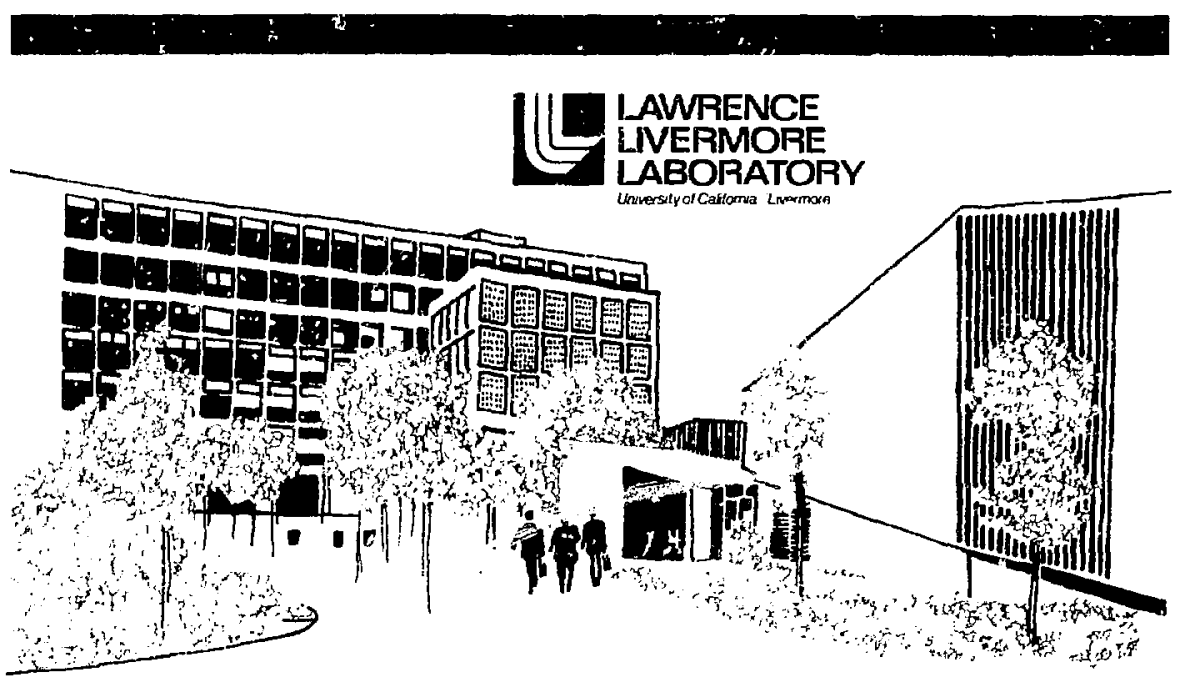

$\because$

\section{MASTER}




\title{
世4 \\ L_AWRENCE IIVERMORE I_ABORATORY
}

Unversity of Calfornia Livermore.Califorra 945til

UCRL. $\$ 2660^{\circ}$

\section{AN INTRODUCTION TO SELF-INDUCED RAINOUT}

\author{
C. R. Molenkump
}

MS. dale: Rebruary 1979 


\section{AN INTRODUCTION TO SELF-INDUCED RAINOUT}

\section{ABSTRACT}

Self-induced rainout is the rapid scavenging and deposition of radioactive weapons debris by a precipitating convective cloud. It is caused by detoration of a nuclear weapon. Results from a theoretical calculation using a cloud scavenging model indicate that self-induced rainout car occur in appropriate atmospheric conditions. Observational evidence from Hiroshima and Nagasaki indicate that self-induced rainout may have occurred in those cities.

For the past six years we have been involved in a ratinoul research program to assess the potential collateral damage due to rainout in a tactical context. Three major components of our research are

- Studies of the microphysical attachment processes whereby small radioactive debris particles become incorporated in cloud droplets and raindrons,

- Investigation of dynamic interactions between rain clouds and debris clouds that lead to entrainment of debris into regions of precipitation wherc scavenging and deposition can occur,

- Aralysis of scavenging climitology that translates rain frequr... $y$ and characteristics into eslimates of the occurrence and magnitude of deposited radiation doses.

We have concluded from previous research that a militarily significant collateral-damage hazard would occur approximately 10 per cent of the time in Western Europe.' $\wedge$ s a result of this conclusion. the Army Nuclear Agency is currenty incorporating in fieid manuals a section on rainout collateral damage.

Several years ago we conjectured that detonation of a nuclear weapon could initiate the formation of a convective cloud that would precipitate and rapidly scavenge and deposit a large amount of radioactive debris on the ground. To investigate the consequences of such an occurrence, which we call self-induced rainout, we used a convective cloud scavenging model that we had developed to study scavenging by naturally occurring convective clouds. This model simulates the life cycle of a convective cloud, including the development of rain and the scavenging and deposition of Jebris. It operates by numerically integrating with time Eulerian, finite-difference approximations of the equations of motion and thermal energy Development of precipitation is included by solving massconservation equations for water vapor and liquid water in several drop-sise categories. Interactions of debris particles with drops are represented in the model by a similar set of mass-conservation equations for radioactive debris. Initial conditions used to start the model include it motionless. conditionally unstable atmosphere perturbed with a local bubble of warm air. In sirfulitions of natural convection, this buoyancy perturbation is assumed to arise because of atmospheric inhomogeneity or local heating: for simulations of self-induced rainout, the buovancy perturbation is assumed to result from the local heating due to detonation of a nuclear weapon. Our simulation of a l-kt free air burst, using, a sounding from Germany on a day when there vere scattered convective showers. predicted that self-induced rainout would occur. Radiation dose tale patterns $\rightarrow-$ hour after detonation are given in Fig. I. Our model confirmed the conjecture that self-induced rainout could occur and could deposit militarily significant amounts of radioactivity on the ground.

Because of this result, we made a cursory look at weapons test data to see if we could find any observations of self-induced rainout, but none were found. This is not particularly surprisi Ig, because tests in Nevada were always timed ts avoid any early precipitation. as is relatively easy to do in the arid climate of Nevada. In the Pacific there were relatively few low-yield free air bursts. From the observation points. which were typically 10 or more miles upwind of th. burst point, we have found no 


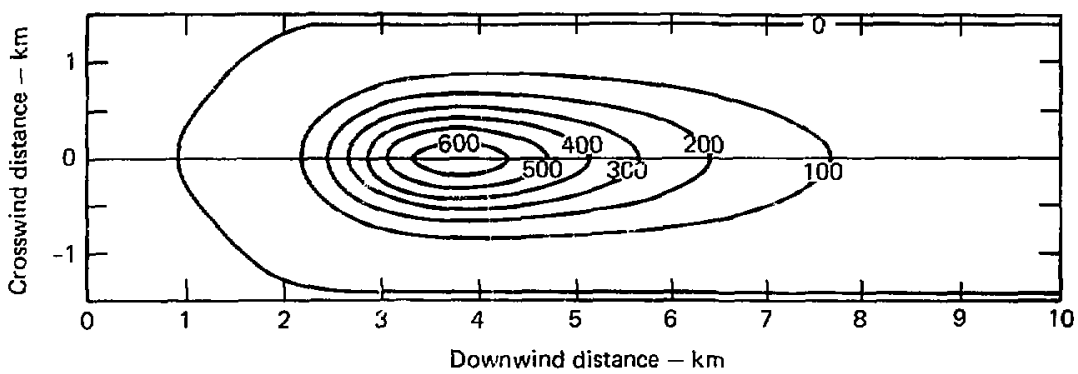

FIG. 1. Radiation dose rate contours on the ground one hour after detonation, assuming a $5 \mathrm{~m} / \mathrm{s}$ wind. Contour Iavels are in rads per hour.

reports of early rainout. but that is not surprising either, hecause no one ever looked for it. It is not likely that rain would have been observed between the typically low cloud bases in the Pacific and the ocenn surface from such greal distances. There are observations of precipitation being causcd by forest fires and agricultural burning, and these observations lend some support to our hypothesis that salfinduced rainout could occur.

L.ast spring we acquired a report by John $\wedge$. Auxicr entitled /chiban: Radiation Dosimelry for the Survivors of the Bombings of Hiroshima and Nagasaki: ${ }^{2}$ This report mentions a phenomerion called "black rain." Subsequent investigation of this phenomenon has shown that rainout of fresh radioactive debris occurred at both Hiroshima and Nagasaki. It was not raining at the time of the burst; in fact, one criterion for release of the bombs was visual sighting of the target. Rain started falling about 20-60 min after the time of burst, which is just what convective cloud models predict for the linte required by a cloud to develop to the precipitation stage, and rain fell only at locations downwind of the burst point. Rain amounts were large (in fact. there was local flooding at Hiroshima), and rain continued through most of the day. Large anounts of soil and soot were deposited with the rain; hence the name "black rain." An additional important fact is that intense fires raged in the cities all day and into the evening. These fires probably had the effect of forcing development of convective precipitation throughout the day.

Dose patterns of deposited radivactivity as measured by the U.S. team ahout 60 days aftes detonation are shown in Figs. 2 and 3. The cortours at the center of burst are tue to initial neutron-in luted radioactivity and gamma rays. The rainout-cie posited debris eame down several kilometres downwind (west of center of burst at Hiroshima and east of center of burst at Naga'iaki) and contained isotopes characteristic of iresh loomb debris. If one uses the $\mathrm{t}^{-1.2}$ decay law for this residual radiation, the infinite dose is 1.4 rad at Hiroshima and 30 rild at Nigasaki. The applicability of the $\mathrm{t}^{-1.2}$ law to entrapolate doses backwards in time is doubtful hecause of the large amount of precipitation in the intervening 60 days, including that from it typhoon that passed through the area. Other data from the survey of survivors and their symptoms of rudiation sickness suggest that people exposed to rain may have received larger doses. Table 1 compares the reported nonincidence of radiation effects for a con: rol population of survivors who received initial exposures up to 20 rad with ari experimental population who received similar initial exposures and an additional unknown exposure because they were in the rilin. Those people who received rainout exposures suffered much higher incidences of radiation effects and reported suffering symptoms characteristic of doses up to $100 \mathrm{rad}$. 


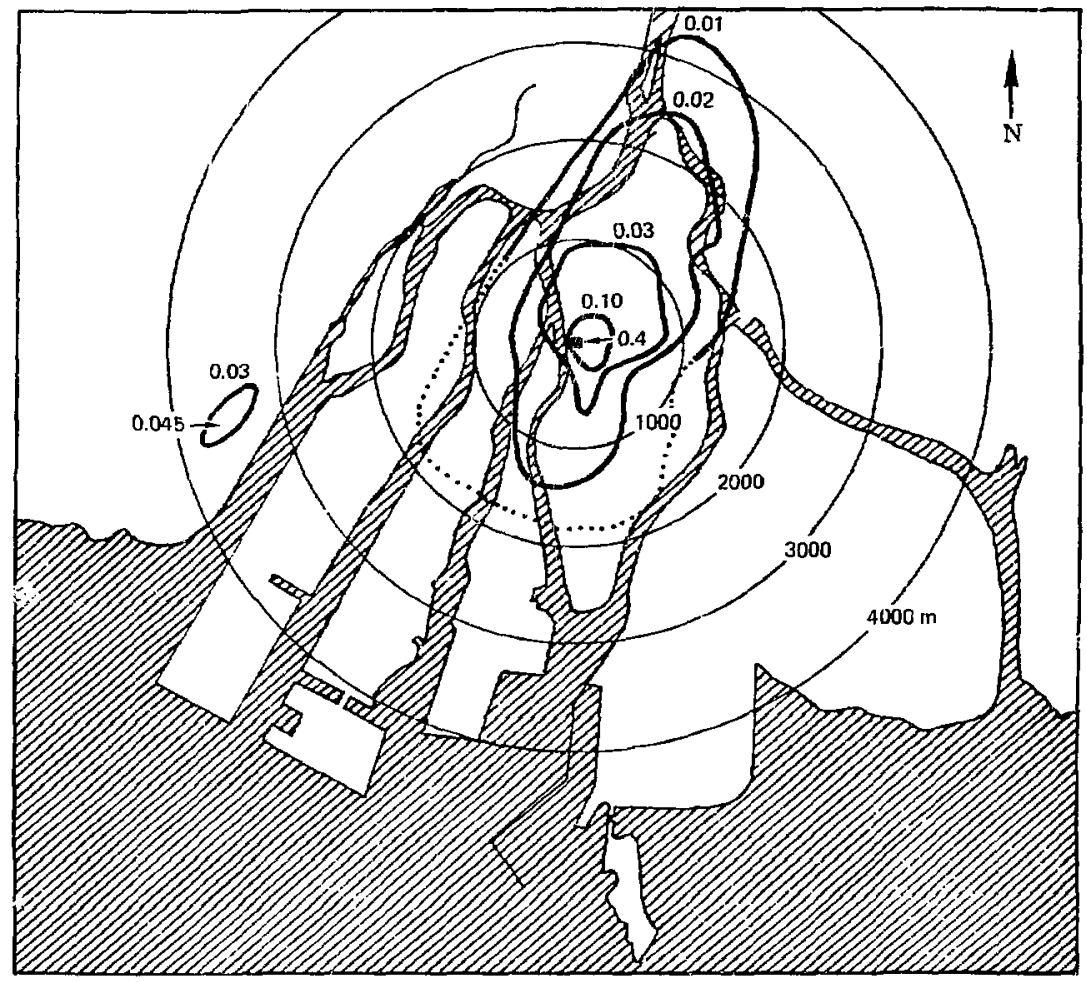

FiG. 2. Isodose contours evaluated in milliroentgens per hour for October 3-7, 1945, at Hiroshima. ${ }^{3}$

The conclusions we have drawn so far are that rainoul of fresh weapons debris occurre ${ }_{2}$ at Hitoshima and Nigasiki. that this precipitation was injtiated by the weapon itself, by the ensuing fires, or by both, and that doses received by people exposed to rainout were low to moderate.

In the future we intend to continue our analysis of Hiroshima und Nagasaki rainoul and weather datal and. when sufficient data are ilvailable, to simulate these everts with our convective cloud scavenging model. Because this scavenging model was not designed to simulate nucluar weapons. several model assumptions are violited in applying the model to these situations. Therefare. we intend to develop a self-induced rainout model that will simulite the rise of a weapons cloud intu tite amhitent environment and the seavenging and depositiun of weapens debris. With such a model we will be better able to assess the effects of self-induced ratinoul in a tactical context. 


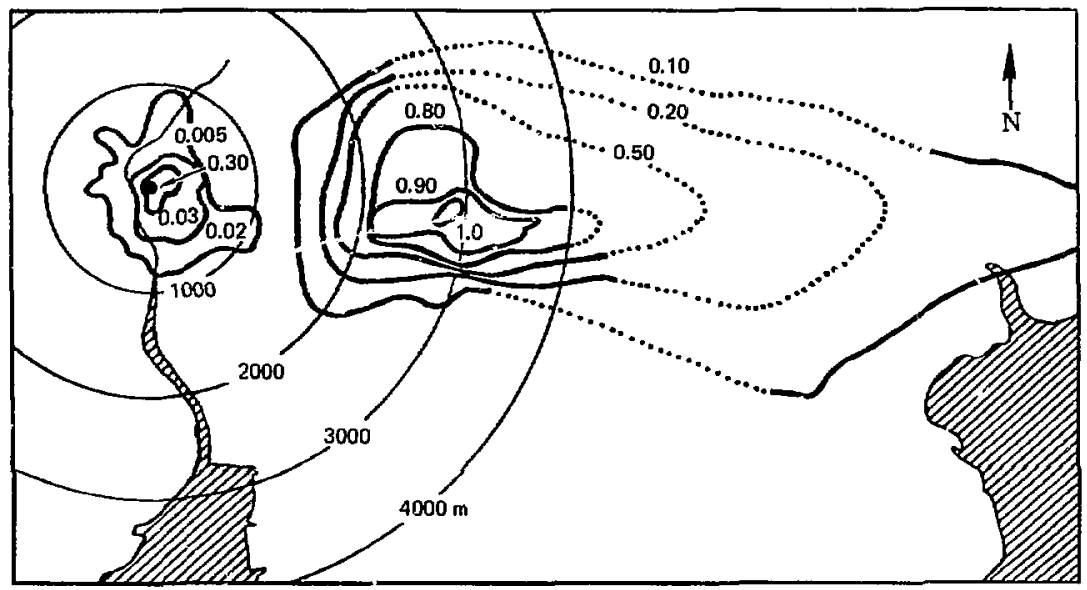

FIG. 3. Isodose contours evaluatel in milliroentgens per hour for October 3-7, 1945, at Nagasaki. ${ }^{3}$

TABLE 1. Reported nonincidence of initial radiation effects. ${ }^{3}$

\begin{tabular}{ccc}
\hline $\begin{array}{c}\text { Initial } \\
\text { exposure, } \\
\text { md }\end{array}$ & $\begin{array}{c}\text { Percent of population reporting } \\
\text { nonincidence of initial radiation effects }\end{array}$ \\
\cline { 2 - 3 } $\begin{array}{c}\text { Experimenta } \\
\text { population, } \\
\%\end{array}$ & $\begin{array}{c}\text { Control } \\
\text { population, } \\
\%\end{array}$ \\
\hline 1 & 37.8 & 99.0 \\
$1-10$ & 30.6 & 96.4 \\
$10-20$ & 24.4 & 95.4 \\
\hline
\end{tabular}

Data taken from Ref. 4.

$b_{287}$ survivors who received an initial exposure, as shown in column 1 , and an additional unknown exposure becuuse diey were in the rain.

$c_{16,045}$ survivors who received only an initial exposure, as thown in column 1, and who were not in the rain. 


\section{REFERENCES}

I. J. B. Kriox and C. R. Molenkamp. Investigations of the Dose to Man from the Wet Deposition of Nuclear fermsts. I.awrence Livermore Laboratory. Livermore, CA. LCRL-76109 ([977).

2. J. A. Auvier. KHIBAN Radiation Dosimetry for the Survivors of the Bombings of Hiroshima and Nagasaki. Energy Research and Developmenl Administration. Washinglon. DC. Rept. TID.27080 (1977).

3. L. T. Arakawa, Radiation Dosinetry in Hiroshina and Nagasaki stomic Bomb Survivors, Atomic Bomb Casualty Commission. Hiroshima-Nagasaki. Japan. Techniral Rep1. 14-59 (1959).

4. II. Yamada and T. D. Jones. An Examination of A-Bomb Survivors Exposed so Falloul Rain and a Comparison to a Similar Control Population, Oak Ridge National Laboratory, Oak Ridge. TN. Rept. OR.NL.TM-4017 (1972).

RW:jm 